\title{
Potential of Bamboo Stem Ash as Supplementary Cementitious Material in Concrete Production
}

\author{
Chijioke Christopher Ikeagwuani, *Donald Chimobi Nwonu, \\ Daniel Adejoh Obetule, Matthew U Omeje, Tonoejit Festus \\ Civil Engineering Department, University of Nigeria, Nsukka \\ Enugu, Nigeria
}

\begin{abstract}
Rising costs and a growing sense of environmental consciousness are among the important factors that drive the search for alternative materials in concrete production. This study investigated the potential of Bamboo Stem Ash (BSA) as a supplementary cementitious material in concrete production. This was done by varying the percentage composition ratios of Bamboo Stem Ash to Ordinary Portland Cement (OPC) in both concrete and mortar at $5: 95,10: 90,15: 85,20: 80,25: 75$

and $30: 70 \%$. The concrete cubes were prepared using binder/sand/stone ratio of 1:2:4 and water/cement ratio of 0.6 while the mortar cubes were prepared using a binder/sand/water ratio of $1: 3: 0.5$. Results from the study show that the best combination of the BSA to OPC ratio for optimum concrete strength is $10 \%: 90 \%$ for which the compressive strength at 28 days of curing was $22.88 \mathrm{~N} / \mathrm{mm}^{2}$ in comparison with $24.58 \mathrm{~N} / \mathrm{mm}^{2}$ obtained for the control sample. For mortars replaced with the varied percentages of BSA, a slow rate of strength gain was observed even after curing for 28 days.
\end{abstract}

Keywords- Bamboo stem ash; Cement; compressive strength; Concrete; Mortar; Pozzolana.

\section{INTRODUCTION}

The contributions of engineers towards a sustainable environment is perhaps best exemplified by their consistent search for engineering materials that are cost effective, possessing alternative uses and with little or no adverse effect on the environment. To this end, researchers particularly in the field of engineering, work relentlessly to find better and novel ways engineering materials can be efficiently and prudently utilized. This practice discourages heavy reliance on a single engineering material by providing alternative and economical materials which can serve similar purpose. Concrete is one of such areas of interest.

Concrete, which is a mixture of cement, aggregate, and water $[1,2]$, is according to [3, 4], the world's most widely used man-made product. It is estimated that the worldwide production of concrete per annum is in excess of 10 billion tonnes [4]. In the US alone, at least two tonnes of concrete per capita are produced each year [4]. There are several properties of concrete which makes it indispensable in construction. Such properties include its compressive strength, durability, and fire resistance. There is virtually little or no construction work done without the use of concrete. An essential constituent of concrete is Portland cement. It is known that concrete in itself possesses little or no harmful environmental effect, as opposed to cement whose worldwide production generates some $7 \%$ of the world's carbondioxide $\left(\mathrm{CO}_{2}\right)$ emission [4]. This is in fact the subject of studies by the following researchers [4, 5, 6, and 7] where it is shown that in the Cement industry, even with the ratio of $\mathrm{CO}_{2}$ to that of cement produced by mass at almost $1: 1$, demand growth for cement and concrete additives continue to rise worldwide, at some estimated $7.2 \%$ annually. This growing demand for cement and the rate at which its raw materials (mainly limestone) are converted to finished cement products come at some economic disadvantage and cost to the environment. The need therefore, to deemphasise this demand by sourcing for relatively cheaper, but highly efficient alternative cementitious materials like condensed silica fume, fly ash, ground granulated blast furnace slag, and pozzolana, cannot be fully overemphasised. This is the major impetus for this study.

The American Society for Testing and Materials, ASTM describes a pozzolana as "a siliceous or siliceous and aluminous material which in itself possesses little or no cementitious value, but which will, in a finely divided form and in the presence of moisture, chemically react with lime at ordinary temperature to form compounds possessing cementitious properties" [8]. There is a renewed and diverse interest in the use of pozzolana in concreting worldwide because researches have overtime shown that pozzolana have the following advantages when employed in concrete technology: low costs; low heat of hydration and thermal shrinkage; improvement in its resistance to attack by sulphate present in soils and seawater; improve durability; lower susceptibility to dissolution and leaching; improve workability [1]

Significant research has been done to assess the pozzolanic properties of different agricultural waste products such as sugar cane bagasse [9, 10], sugar cane leaves [11], corncob [12], oil palm ash [13], rice husk $[14,15]$, banana leaves [16], elephant grass [17], bamboo leaves $[18,19,20]$. But on the subject of bamboo Stem however, scientific literature is scarce. A study by [21] is suggestive of the cementitious value of bamboo stem ash (BSA). The results of their studies show that the strength activity index obtained from $4 \times 4 \times 16 \mathrm{~cm}^{3}$ prismatic mortar samples partially replaced with $10 \%$ BSA calcined at $600^{\circ} \mathrm{C}$, was in conformance with the requirements of [8]. However [21] recommend additional 
experiments to study the influence of BSA on consistency, hydration and durability of cementitious material using higher amounts of ashes and or natural pozzolana.

Bamboo stem is an important engineering material used daily in the local construction industries, where they serve essentially as scaffolds. When these stems are weak, and can no longer support load, they are discarded as waste from whence they are used locally as cooking fuel or left to pollute the environment. Growing environmental consciousness as well as advances in science and technology continues to account for a steady decline in the use of fire woods (bamboo stems and other wood trunks) and a paradigm shift towards the use of green energy as cooking fuel. Consequently, a number of used bamboo trunks are left to increase astronomically with its attendant adverse effect on the environment. As an agricultural waste, bamboo stem has the potential to contribute positively to the environment through the prospective pozzolanic activities of its ash [21]. The burning of bamboo trunks under controlled conditions, for its ash, could take care of the environmental pollution caused by its waste, and provide an alternative to cement at a reduced cost. Bamboo plant is readily available in so many countries of the world and survives under severe conditions.

This present study investigates the cementitious value of BSA in concreting, by partially replacing OPC constituent of concrete and mortar samples with 5, 10, $15,20,25$, and $30 \%$ BSA. The samples were tested for their consistency and compressive strength as per the recommended standards and their performance measured against same known standards.

\section{MATERIALS AND METHODS}

\section{A. Ordinary Portland Cement}

The Dangote group cement was the OPC used in this research study. It is locally available in Nigerian markets with an average bag weight of about $50 \mathrm{~kg}$. The chemical constituents of the cement satisfies the requirements of [22]. The cement used was sourced from a dealer in Ogige market in Nsukka urban. The geographical map of Nigeria shows that Nsukka is located at latitude $6^{\circ} 51^{\prime} 24^{\prime \prime} \mathrm{N}$ and longitude $7^{\circ} 23^{\prime} 45^{\prime \prime} \mathrm{E}[23,24]$.

\section{B. Bamboo Stem Ash}

The BSA used in this study was obtained from the combustion of the waste bamboo stems at controlled temperatures of $800^{\circ} \mathrm{C}$ for 2 hours. The bamboo stems were gathered as wastes from construction sites in Nsukka urban, Nigeria. The stems were neatly gathered, cut and packed in polythene bags to avoid contact with moisture, from where they were conveyed for combustion to the Department of Civil Engineering Laboratory, University of Nigeria Nsukka.

\section{Water}

Water from the curing tank of the Civil Engineering laboratory, University of Nigeria Nsukka was used, for both the mixing and for the curing of the sample cubes.
The organic and inorganic material constituents of the water are within tolerable limits and are in accordance with [25].

\section{Aggregate}

The sand used was obtained from Akachele hill, Obimo, Enugu state. Obimo is located within latitude $6^{\circ} 49^{\prime} 36^{\prime \prime} \mathrm{N}$ and longitude $7^{\circ} 19^{\prime} 15^{\prime \prime} \mathrm{E}$ The sand has a specific gravity of 2.61 and moisture content of 2.52 . The coarse aggregate was sourced from a quarry at Isiagu in Oha-Ukwu Local Government Area of Ebonyi State within latitude $6^{\circ} 28^{\prime} 21^{\prime \prime} \mathrm{N}$ and longitude $8^{\circ} 0^{\prime} 10^{\prime \prime} \mathrm{E}$. It was bought from local dealers in Nsukka Local Government. It has a specific gravity of 2.783 and average water absorption of 0.95 . Both the sand and coarse aggregate conform to the specifications of [26].

\section{E. Carbonization of the Bamboo Stem}

The bamboo trunks used in this study were collected from various construction sites in Nsukka urban. The stems were sun dried for 24 hours to avoid the ingress of moisture. The trunks were cut into smaller sizes and placed in a furnace where they were incinerated under controlled conditions at a temperature of $800^{\circ} \mathrm{C}$ for a duration of 2 hours. The burnt trunks were allowed to cool for 5 hours. After cooling, the resulting ash was first sieved through $2.36 \mathrm{~mm}$ diameter sieve and subsequently sieved through $0.075 \mathrm{~mm}$ diameter sieve to produce fine particles that would be suitable for concreting such as is shown in Fig. 1. Care was taken to avoid the sieved ash coming in contact with moisture.

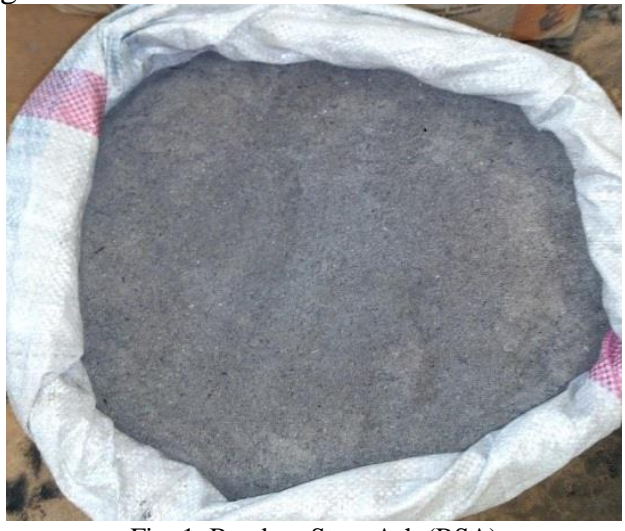

Fig. 1. Bamboo Stem Ash (BSA)

\section{F. Sieve Analysis}

The sieve analysis of the fine aggregates was conducted in accordance with the requirements of [27]. British Sieve numbers 4, 7, 14, 25, 52, 100, and a pan were used. A weighing balance was then used to record the weight of aggregate retained on each sieve from which the particle size distribution curve was deduced.

\section{G. Specific Gravity}

This test was carried out for both fine and coarse aggregates in the laboratory in accordance with the specification in [28], using two density bottles in each case. The specific gravity of the aggregate was then determined as the average of the two values obtained from the two bottles in either case. 


\section{H. Moisture Content}

This test was carried out for the fine aggregate in the laboratory according to the specifications of [29] using three moisture cans of known mass. They were filled with the fine aggregate, weighed, oven dried at temperatures of $100^{\circ} \mathrm{C}$ to $110^{\circ} \mathrm{C}$, and weighed again for their dry mass from where their moisture content was deduced. The moisture content of the fine aggregate was then taken as the average of the three samples.

\section{Setting Time}

Setting time is the time required for cement paste to be stiffened to a defined consistency. The initial and final setting time of the cement paste was conducted using a Vicat's apparatus in line with the specifications of [30]. A representative sample of about $500 \mathrm{~g}$ of the cement paste was mixed with $150 \mathrm{~g}$ of water, predetermined from the consistency test, and placed in the mould of the Vicat's apparatus. With the mould in place, a $1 \mathrm{~mm} x$ $1 \mathrm{~mm}$ square needle attached to the plunger is allowed to fall freely until the depth of penetration measured from the Vicat's scale is $5 \mathrm{~mm}$. The needle was then replaced with a needle of annular collar and the procedure repeated to deduce the initial and final setting times.

\section{J. Preparation of Concrete and Mortar Cubes}

In this study, the tests were carried out in accordance with the specification of British Standards [22], [25], [27], [28], [29], [30] and [31]. Preliminary tests were carried out initially on the OPC and aggregate samples to determine their setting time and physical properties respectively. These tests include: setting time test for the cement, sieve analysis for the fine aggregate, specific gravity and water absorption for the coarse aggregate, specific gravity for the fine aggregate, and moisture content tests. In this study, two categories of samples were produced-concrete cube samples and mortar cube samples. 108 cubes were cast in total, 3 at every given curing age following the minimum specification of [31] for each percentage BSA replacement. Samples of the cubes are shown in Fig. 2.

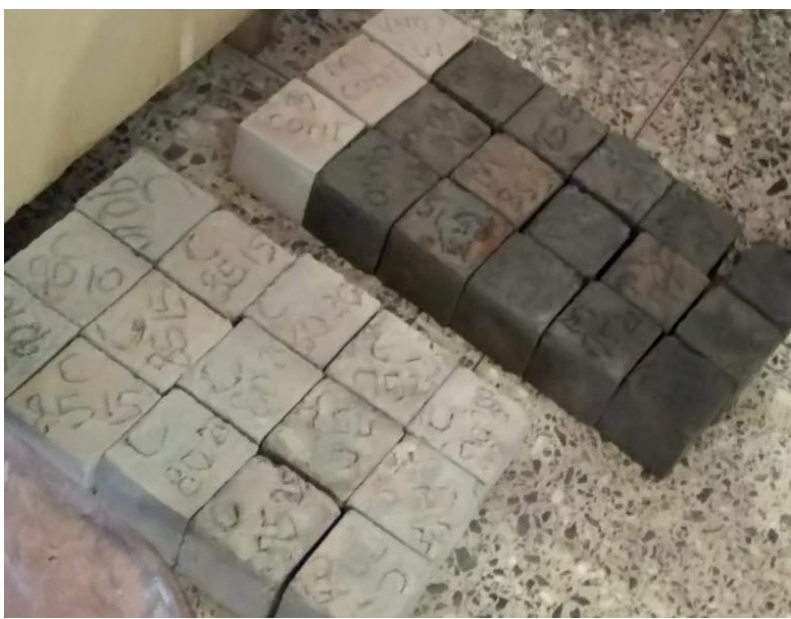

Fig. 2. Concrete and Mortar cubes
The cube sizes of the various categories were each of $100 \mathrm{~mm} \times 100 \mathrm{~mm} \times 100 \mathrm{~mm}$, and their various compressive strengths were obtained. The compressive strengths were determined after 7, 14, 21 and 28 days of curing for the various partial replacements of OPC with BSA. This was done at $5: 95,10: 90,15: 85,20: 80$, $25: 75$ and $30: 70 \%$ of bamboo stem ash to cement respectively. The concrete cubes were prepared using binder/sand/stone ratio of 1:2:4 and water/cement ratio of 0.6 to ensure optimum workability, while the mortar cubes were prepared using a binder/sand/water ratio of $1: 3: 0.5$. The curing of the samples was done by immersing in water for 7, 14, 21 and 28 days.

\section{K. Slump Test}

The consistency of the fresh concrete and fresh mortar was conducted according to the specifications of [32]. This indirectly checks, that the correct amount of water has been added to the mix.

\section{Compressive Strength Test}

The compressive strength tests were carried out in the laboratory using Qualitest automatic concrete compression testing machine, shown in Fig. 3, for the cured cube samples of both concrete and mortar as per the specifications of [33]. Three specimens were used for each curing period and percentage replacement. The compressive strength of the sample was computed as the average of the strength value for three specimens.

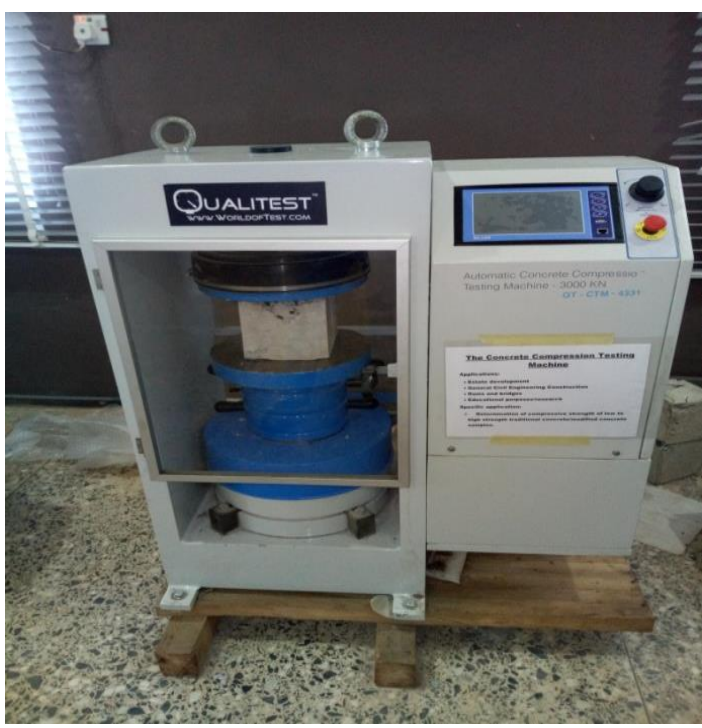

Fig. 3. Automatic concrete compression testing machine

\section{RESULTS AND DISCUSSION}

\section{A. Preliminary Test Results}

Results of the particle size distribution curve for the geometric analysis of the fine aggregate is shown in Fig. 4. The sand was found to give a fineness modulus of 3.21 , with values for coefficient of uniformity, $\mathrm{C}_{\mathrm{u}}$ and coefficient of gradation, $\mathrm{C}_{\mathrm{c}}$ of 3.2 and 1.3 respectively, hence it is classified as poorly-graded sand [34]. The specific gravity and average moisture content for the fine 
aggregate was 2.61 and $2.52 \%$ respectively. For the coarse aggregate, results from the preliminary tests show that it had an average specific gravity of 2.783 and an average apparent specific gravity of 2.86. Also, the average water absorption for the coarse aggregate was found to be $0.95 \%$.The results obtained from tests conducted on the Ordinary Portland Cement (OPC) showed that the cement performed satisfactorily in line with the specifications of [22]. The initial and final setting time for the cement was found to be 34 minutes 30 seconds and 1 hour 15 minutes 27 seconds respectively.

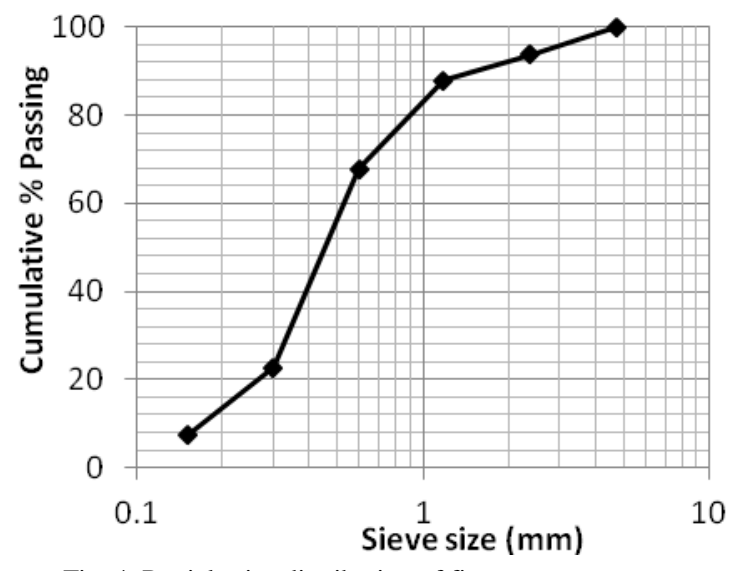

Fig. 4. Particle size distribution of fine aggregates

\section{B. Slump Test}

The results for the slump test on fresh concrete and mortar are shown in Fig 5 and 6 respectively. The slumps obtained for concrete were in the range of $15 \mathrm{~mm}$ - 30mm, while those obtained for mortar were in the range of $3 \mathrm{~mm}-6 \mathrm{~mm}$. The slump values recorded for both cases of concrete and mortar with $100 \%$ cement were higher as compared to those with varied percentages of replacements. Higher amounts of BSA replacements were observed to lower the slump values achieved for both concrete and mortar. This may be due to the gradation of the BSA which would have allowed for textures with a greater surface area as opposed to the OPC in the mix. Textures with greater surface areas have been known to reduce workability. However, the consistency achieved for the concrete and mortar samples with 10 and $15 \%$ BSA replacements were found to compare favourably with those of the 100 percent concrete and mortar samples with percentage differences of $20 \%$ and $16 \%$ respectively. This results appear to be in agreement with those obtained by [20] for bamboo leaf ash (BLA).

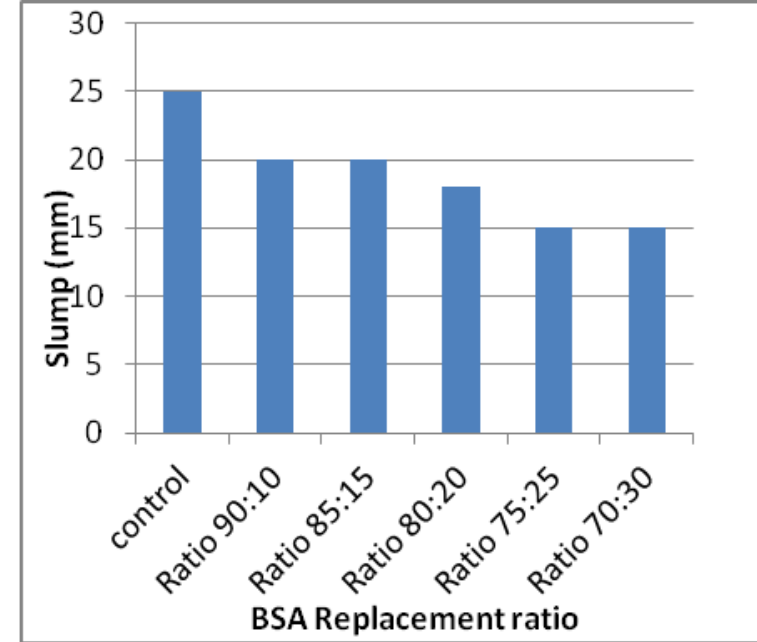

Fig. 5. Slump against BSA Replacement for Concrete

\section{Compressive Strength}

The results for the compressive strength test for both concrete and mortar for the various curing ages, are shown in Figs. 7 and 8 respectively. The compressive strength of both concrete and mortar cubes were found to have decreased with increasing percentage of BSA. In both concrete and mortar, the compressive strength value obtained for the $100 \%$ cement sample exceeded those with BSA replacements. The compressive strength of concrete with BSA replacements of 10 and $15 \%$, is found to increase progressively with curing age as with that of the OPC. The trend for concrete samples with 20\%-30\% BSA was an initial decrease with curing age followed by a marked increase most noticeable after the 28th day of curing.

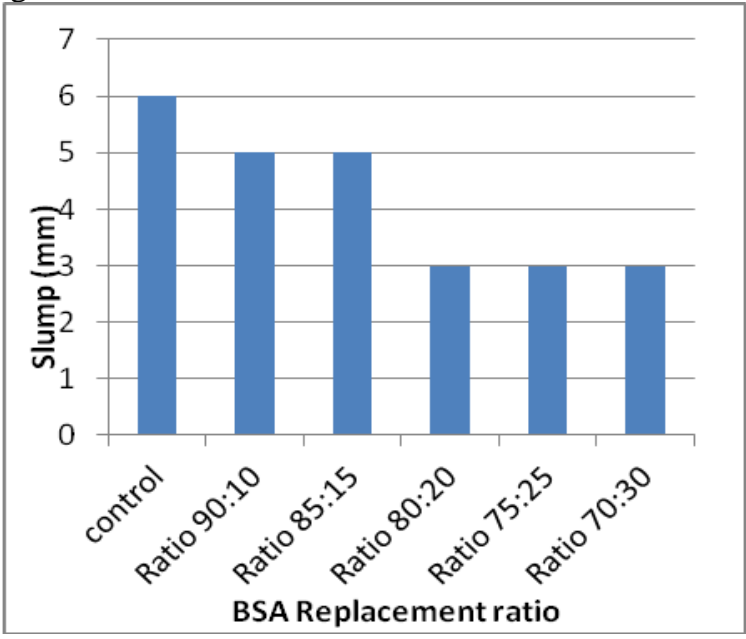

Fig. 6. Slump against BSA Replacement for Mortar

The concrete samples with BSA replacement of 10 and $15 \%$ were found overall, to give characteristic compressive strengths (with percentage differences of $6.9 \%$ and $17.8 \%$ respectively) that are comparable with that of the control concrete after the 28th day of curing. For the mortar samples, the compressive strength recorded for the BSA replacements were significantly lower than those obtained for the $100 \%$ mortar sample. The results show an initial decline in strength up to 21 curing days, closely followed by an increase in the 
mortar strength after the 28th curing day. This is in agreement with $[20,21]$. There is however a noticeable contrast with the compressive strength obtained here for mortar with $10 \%$ BSA replacement with that obtained by [21] after 28 days of curing. The reduction in strength recorded for both concrete and mortar samples are traceable to the effects of specimen shape and size on compressive strength. The decrease in strength with curing age recorded for the mortar samples, may be attributed to weather attack on BSA. Also, the delayed strength gain of both the concrete and mortar mix may be due to higher amounts of cement replaced with BSA. Higher percentages of BSA in the mix introduce larger surface areas for the cement to react with during hydration and pozzolanic reaction, thereby delaying the formation of Calcium Silicate Hydrates (C-S-H) which according to [21] is responsible for mechanical strength. This appears to be in agreement with [35].

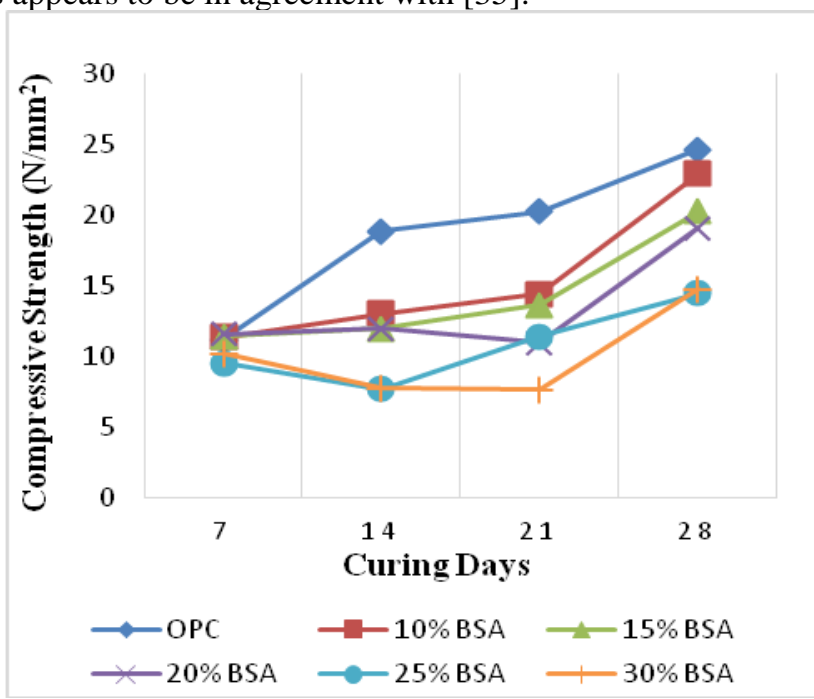

Fig. 7. Compressive strength against curing days for concrete

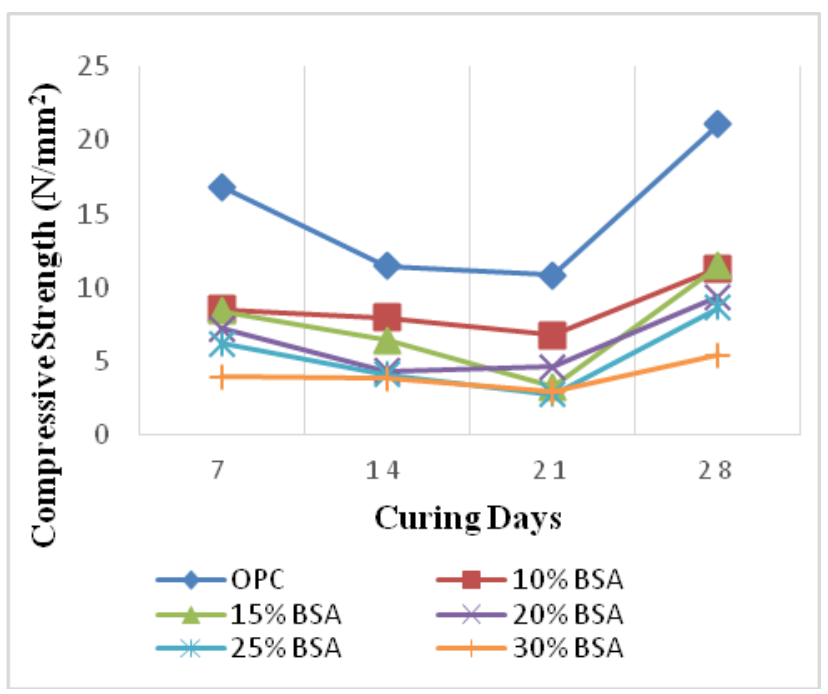

Fig. 8. Compressive strength against curing days for mortar

\section{CONCLUSION}

This research has attempted objectively, to examine the potential of the bamboo stem ash (BSA) as a partial replacement for cement in concrete production. The tests conducted, allow the following conclusions to be drawn:

1. The results of the slump test show that the consistency achieved with various percentages of BSA replacements for both concrete and mortar fall well within the requirements of [32].

2. The compressive strength for concrete with $10 \%$ and $15 \%$ BSA replacement was found to have compared favourably with that of the control concrete after 28 days of curing, with decrease of about $6.9 \%$ and $17.8 \%$ respectively.

3. The compressive strength for the mortar cubes however showed a characteristic decline with curing age, falling noticeably below the control samples even after 28 days of curing, with recorded decrease of about $46.5 \%$ and $45.7 \%$ for $10 \% \mathrm{BSA}$ and $15 \%$ BSA respectively. This strength decline, can be improved as also noted by [20], with the addition of super plasticizers to achieve early strength.

4. On the whole, with the results obtained from this research, the cementitious value of the BSA for partially replacing cement in concrete production is justified. Its adoption into concreting will help to check the environmental problems associated with its waste bamboo stem, and ultimately reduce the levels of $\mathrm{CO}_{2}$ emission associated with the production of cement. This is the crux of every sustainable effort.

\section{CONFLICT OF INTEREST}

On behalf of all authors, the corresponding author states that there is no conflict of interest.

\section{ACKNOWLEGMENT}

The authors wish to thank the Nigerian liquefied natural gas (NLNG) company for their generous provision of the state-of-the-art laboratory equipment that were employed to perform the experiments in this study.

\section{FUNDING}

The authors did not receive any funding for this research.

\section{REFERENCES}

[1] Shetty, M. S. Concrete Technology Theory \& Practice. S. Chand \& company ltd, Ram Nagar, New Delhi, 2000.

[2] Arthur, H. N. \& George, W. Design of Concrete Structures, McGraw-Hill, New York, 1986.

[3] Shah, S. P. "Recent trends in the science and technology of concrete", Rilem Proceedings, E \& FN spon, London, 1995, pp. 118

[4] Meyer, C. "Concrete Materials and Sustainable Development in the USA".Structural Engineering International, 2004.

[5] Hanle, L.J., Jayaraman, K.R., Smith, J.S. " $\mathrm{CO}_{2}$ emissions profile of the US cement industry". US Environmental Protection Agency, Pennsylvania, 2004.

[6] Van Oss, H., Padovani, A.C. "Cement manufacture and the environment". J Ind Ecol 6:89 - 106. 2002 
[7]"World Cement- Demand and Sales Forecasts, Market Share, Market Size, Market Leaders", The Freedonia Group https://www.freedoniagroup.com/World Cement.html Retrieved October 2, 2018.

[8] ASTM Standard C618, "Standard Specification for Coal Fly ash and Raw or Calcined Natural Pozzolan for Use in Concrete", ASTM International, West Conshohocken, PA, 2012.

[9] Ganesan, K., Rajagopal, K., Thangavel, K. "Evaluation of bagasse ash as supplementary cementitious material", Cem Concr Comp 29:515-524, 2007.

[10] Singh, N.B., Singh, V.D., Rai ,S. "Hydration of bagasse ashblended Portland cement", Cem Concr Res 30:1485-1488, 2000

[11] Singh, N.B., Das, S.S., Singh, N.P., Dwivedi, V.N. "Studies on SCLA composite Portland cement", Indian J Eng Mater Sci 16:415-422, 2009.

[12] Adesanya, D.A. "The effects of thermal conductivity and chemical attack on corn cob ash blended cement". Prof Build 66:3-10, 2001

[13] Sata, V., Jaturapitakkul, C., Kiattikomol, K. "Utilization of palm oil fuel ash in high-strength concrete", J Mater Civ Eng 16:623628, 2004.

[14] Cordeiro, G.C., Toledo-Filho, R.D., Fairbairn, E.M.R. "Use of ultrafine rice husk ash with high-carbon content as pozzolan in high performance concrete", Mater Struct 42:983-992, 2009.

[15] Zhang, M.H., Malhotra, V.M. "High-performance concrete incorporating rice husk ash as a supplementary cementing material", ACI Mater J 93:629-636, 1996.

[16]. Kanning, R.C., Portella, K.F., Braganca, M.O., Bonato, M.M., Dos Santos, J. "Banana leaves ashes as pozzolan for concrete and mortar of Portland cement", Constr Build Mater 54:460-465, 2014.

[17]. Nakanishi, E.Y., Frias, M., Martinez-Ramirez, S., Santos, S.F., Rodrigues, M.S., Rodriguez, O., Savastano, J.H. "Characterization and properties of elephant grass ashes as supplementary cementing material in pozzolan/ $\mathrm{Ca}(\mathrm{OH})_{2}$ pastes", Constr Build Mater 73:391398, 2014.

[18] Dwivedi, V.N., Singh, N.P., Dasa, S.S., Singh, N.B. "A new pozzolanic material for cement industry: bamboo leaf ash", Int $J$ Phys Sci 1:106-111, 2006.

[19] Fr'as, M., Savastano, H., Villar, E., Sa'nchez de Rojas, M.I., Santos, S. "Characterization and properties of blended cement matrices containing activated bamboo leaf wastes", CemConcr Сотр 34:1019-1023, 2012.

[20] Olutoge F.A., Oladunmoye O.M. "Bamboo leaf ash as supplementary cementitious material", American Journal of Engineering Research vol.6, no.6, 2017.

[21] Rodier, L., Bilba, K., One'sippe, C., Arse'ne, M.A."Study of pozzolanic activity of bamboo stem ashes for use as partial replacement of cement", Journal of Materials and Structures, 58 87. 2017.

[22] BS12. Specification for Portland Cement, British Standard Institution, London, 1996

[23] Ikeagwuani, C. C. "Compressibility characteristics of black cotton soil admixed with Sawdust Ash and Lime," Nigerian Journal of Technology, vol. 35, no. 4, pp. 718-725, 2016.

[24] Ikeagwuni, C.C. "Comparative assessment of the stabilization of Lime stabilized lateritic soil as subbase material using Coconut shell ash and Coconut husk ash" Geotech Geol Eng. https://doi.org/10.1007/s10706-019-00825-0, 2019.

[25] BS EN 1008. Mixing water for concrete. British Standard Institution, London, 2002.

[26] BS 882. Specification for aggregates from natural sources for concrete. British Standard Institution, London, 1992.

[27] BS EN 933- Part 1. Tests for Geometrical Properties of Aggregates. British Standard Institution, London, 1996.

[28] BS 812- Part2. Methods for Determination of Specific Gravity. British standard Institution, London, 1995.

[29] BS EN 1097- Part 5. Tests for Mechanical and Physical Properties of Aggregates. British standard Institution, London, 2008.

[30] BS 196- Part 3. Methods of testing cement. Determination of Setting Time and Soundness. British standard Institution, London, 2016.
[31] BS 1881- Part 125. Methods for mixing and Sampling Fresh Concrete in the Laboratory. British Standard Institution, London, 1983.

[32] BS 1881- Part 102. Method for Determination of Slump. British Standard Institution, London, 1983.

[33] BS 1881- Part 116. Method for Determination of Compressive Strength of Concrete Cubes. British Standard Institution, London, 1983.

[34]Arora, K.R.Soil Mechanics and Foundation Engineering in SI Units, Standard Publishers Distributors, India, 2008

[35] Ikeagwuani, C. C., Obeta, I.N., Nwonu, D.C., Onyia, V.A. Ezema, J.N. "Partial replacement of Cement with Coconut shell ash in sandcrete block", Research Journal of Applied Sciences, Engineering and Technology, 15(6): 206-211, 2018. 